\title{
COGNITIVE ENHANCEMENT THERAPY IN SCHIZOPHRENIA
}

\author{
Syulthoni ZB*, Gunadi IGN** \\ * Dokter Umum, Peserta PPDS I Prodi Psikiatri Departemen/SMF Ilmu Kedokteran Jiwa FK UNAIR/RSUD dr. Soetomo Surabaya \\ **Psikiater Konsultan, Staf Pengajar Departemen/SMF Ilmu Kedokteran Jiwa FK UNAIR/RSUD dr. Soetomo Surabaya
}

\begin{abstract}
Schizophrenia is a chronic, severe, and debilitate mental disorder that causing disability. Factors that causing disability is cognitive impairment. Cognitive impairment caused by disturbance in neurodevelopmental process of the brain that related to Dopaminergic, GABA-ergic, and Acethylcholinergic pathway. Cognitive Enhancement Therapy is additional therapy to recovery the cognitive function. CET facilitated repairmenin socio and non-socio cognitive function, encourage patient behaviour related social condition, develop patient understanding of schizophrenia and the impact on cognitive impairment, and rehabilitation program that characterised of an experiential and exercise to repair the non-social cognitive function (attention, memmory, and problem solving). CET shows improvement in early or late onset of schizophrenia. Patients who got CET can back to work. Now, CET is used for early intervention in cognitive impairment in Schizophrenia. CET was also developed in patients with Schizoaffective, Schizophrenia comorbid with drug abuse, and patientswith autism. Hopefully, the improvement onquality of life patient with schizophrenia can achieve with combination pharmacotherapy and Cognitive Enhancement Therapy.
\end{abstract}

Keyword: Cognitive Enhancement Therapy, CET, Schizophrenia

Corresponding author: Zain Budi Syulthoni, dr.

Dep/SMF Kedokteran Jiwa FK UNAIR/RSUD Dr.Soetomo Surabaya

HP: 08563332986 | email: zainbudi@gmail.com 


\section{PENDAHULUAN}

Skizofrenia adalah gangguan jiwa yang kronis, parah, dan melemahkan. Berdasarkan data, terdapat sekitar $1 \%$ dari sebuah populasi pernah menderita skizofrenia selama hidupnya. Skizofrenia sendiri memberi dampak pada gangguan afek, gangguan persepsi, gangguan kognisi dan fungsi sosial. Terganggunya beberapa hal tersebut membuat pasien skizofrenia sering membutuhkan perawatan yang intensif serta waktu yang panjang. Kebutuhan tersebut dikarenakan kronisitas dan gangguan fungsi tersebut [1], [2]. Menurut Diagnostic and Statistical Manual of Mental Disorders, 4th Edition, Text Revision (DSM-IV-TR), angka kejadian dalam setahun Skizofrenia berkisar antara 0,5-5,0 per 10.000 penduduk. Prevalensi pasien Skizofrenia di Amerika Serikat sekitar 1\% yang artinya, 1 dari 100 orang di Amerika Serikat pernah mengalami Skizofrenia. Sekitar $0,05 \%$ dari total populasi yang bisa mendapat terapi dalam satu tahun terakhir [3].

Kronisitas dari gangguan Skizofrenia merupakan salah satu faktor yang menjadi pertimbangan dari penatalaksanaan. Skizofrenia telah dipandang selama bertahun-tahun sebagai suatu penyakit yang kronis dengan atau bahkan tidak ada harapan untuk sembuh [4-5]. Seki$\operatorname{tar}$ 98\% dari pasien dengan Skizofrenia menunjukkan kemampuan kognisi yang lebih jelek pada tes kognitif daripada tingkat pendidikan yang diterimanya [6]. Gangguan tersebut cukup mempengaruhi fungsi pasien dalam pekerjaan, fungsi sosial pasien, dan manajemen dari penyakitnya sendiri [7]. Defisit kognitif menjadi salah satu aspek sentral dan melemahkan dari Skizofrenia. Hampir seluruh fungsi kognitif terkena dampak seperti memori, atensi, kemampuan motorik, fungsi eksekutif, dan intelegensia [8]. Gangguan kognitif yang terjadi pada pasien skizofrenia membuat skizofrenia menjadi penyakit tiga besar penyebab disabilitas di seluruh dunia di usia dewasa antara 15 sampai 44 tahun. Kognitif sendiri diperlukan untuk fungsi sosial dan okupasional bagi seseorang. Ada dua pilihan remediasi kognitif yang mungkin membantu meningkatkan kemampuan kognitif dan fungsi individu dengan skizofrenia, terapi remediasi kognitif dan dukungan lingkungan [9]. Tujuan artikel ini adalah kemungkinan penggunaan Cognitive Enhancement Therapy dalam perbaikan kognitif pasien skizofrenia.

\section{SKIZOFRENIA}

Gangguan jiwa pertama kali diperkenalkan oleh Emil Kraepelin (1856-1926) dengan istilah dementia prae- cox, menggambarkan kemunduran intelegensi sebelum waktunya disertai gejala klinis berupa waham dan halusinasi. Eugene Bleuler (1911) memperkenalkan istilah Skizofrenia yang berasal dari kata schizos (pecah-belah) dan phren (jiwa). Skizofrenia merupakan sindroma klinis dengan gambaran psikopatologi yang bervariasi. Psikopatologi ini meliputi aspek kognisi, emosi, persepsi, dan perilaku lainnya, bervariasi antara pasien, dari waktu ke waktu, berlangsung lama dan berdampak terhadap kesejahteraan serta kemampuan untuk berfungsi dalam masyarakat $[3,10]$.

Namun, Eack pada tahun 2009 mengemukakan bahwa Skizofrenia adalah sebuah gangguan mental yang kronis dan memberikan kecacatan yang memiliki ciri khas terkait penurunan kognitif, fungsi sehari-hari, dan penyesuaian. Hal yang mempengaruhi baik dari sisi personal dan sosial dari penyakit ini adalah munculnya deteriorasi, dan prognosis yang terus memburuk terkait kondisi yang tidak tertangani. Sehingga yang paling penting adalah intervensi dini untuk mencegah kondisi yang lebih buruk di masa menda$\operatorname{tang}[11,12]$.

\section{Epidemiologi}

Prevalensi Skizofrenia di perkotaan umumnya lebih besar daripada di pedesaan, pada pria dan wanita hampir seimbang tetapi onsetnya lebih muda pada pria. Studi epidemiologis menunjukkan bahwa stresor lingkungan dan psikososial dapat menjadi faktor resiko terjadinya skizofrenia [13]. Prevalensi gangguan jiwa berat nasional di Indonesia sebesar 1,7 per mil, dengan daerah yang tertinggi berada di Aceh dan Daerah Istimewa Jogyakarta masingmasing 2,7 persen sedangkan prevalensi terendah di Kalimantan Barat 0,7 persen [14].

\section{Prognosis}

Salah satu yang memperburuk prognosis dari pasien Skizofrenia adalah masalah kerusakan kognitif. Hampir sekitar 98\% pasien Skizofrenia terkena kerusakan kognitif. Kerusakan kognitif ini berpengaruh pada kualitas hidup pasien untuk kembali normal. Gangguan kognitif yang terjadi diantaranya defisit pada atensi, memori, dan reasoning. Penurunan performa kerja, skill dan menghambat recovery [15].

\section{Penatalaksanaan Skizofrenia}

Penatalaksanaan skizofrenia meliputi aspek biopsiko-sosio-kulturo-spiritual secara menyeluruh, komprehensif dan berkelanjutan dalam jangka waktu lama. 
Psikofarmaka saat ini masih merupakan tatalaksana utama untuk skizofrenia tetapi tidak memberikan hasil yang optimal. Kombinasi obat dan intervensi psikososial akan memberikan manfaat yang lebih baik daripada salah satunya [3].

Beberapa penelitian menunjukkan bahwa setelah 5-

10 tahun setelah hospitalisasi pertama, hanya 10-20\% pasien Skizofrenia yang menunjukkan keluaran baik. Lebih dari 50\% menunjukkan hasil keluaran yang buruk, dengan hospitalisasi berulang, eksaserbasi gejala, episode gangguan mood dan percobaan bunuh diri. Angka remisi sekitar 10-60\%, diperkirakan 20-30\% pasien Skizofrenia dapat menjalani kehidupan normal. Sekitar 20-30\% tetap mengalami gejala sedang dan $40-60 \%$ tetap mengalami gangguan bermakna selama hidupnya [3].

\section{Rehabilitasi Kognitif dan Sosial}

Pemberian antipsikotik pada pasien Skizofrenia sendiri tidak dapat menengembalikan kondisi kognitif pada pasien Skizofrenia. Pemulihan kondisi kognitif pada pasien Skizofrenia ini sangat penting agar pasien Skizofrenia dapat kembali ke fungsi pekerjaan sehati-hari. Salah satu yang bisa dilakukan adalah Cognitive Enhancement Therapy (CET) dimana terapi ini terfokus pada sosial kognitif pada pasien Skizofrenia [16-19].

\section{KERUSAKAN KOGNITIF PADA PASIEN SKIZOF- RENIA}

Skizofrenia saat ini dikenal sebagai sebuah penyakit yang memiliki karakter terjadinya kerusakan neurokognitif dan sosiokognitif yang berhubungan dengan fungsi kehidupan sehari-hari yang menurun. Kerusakan kognitif ini menghambat pasien skizofrenia untuk kembali pulih (recovery). Sekitar $98 \%$ pasien skizofrenia tidak kembali rekoveri disebabkan oleh adanya gangguan kognitif yang mendasari $[15,17]$.

\section{Neurodevelopmental}

Pemahaman terhadap skizofrenia pun mulai bergeser terkait munculnya penelitian terkait disfungsi kognitif tersebut sejak tahun 1980-an. Skizofrenia kini tidak dipandang lagi sebagai gangguan neurodegenerative, namun lebih kearah gangguan neurodevelopmental [20]. Awalnya kelainan neurodevelopmentalbiasanya muncul saat usia prenatal atau usia anak-anak namun ternyata saat ini dikatakan berlangsung hingga remaja dan usia 20 tahunan pada kehidupan seseorang. Tentu saja, proses neurodevelopmental bisa jadi berkembang dengan kondisi yang kurang maksimal, dengan konsekuensi terjadi pembentukan struktur saraf yang tidak sempurna dan tidak sempurnanya fungsi otak, salah satunya adalah kemampuan kognitif. Kondisi stres pada seseorang menciptakan gen yang rapuh sehingga menghasilkan deregulasi dari sistem dopamin dan mencetuskan penyakit. Sehingga, dapat disimpulkan bahwa, strategi untuk mengintervensi secara dini dari stres pada tahap awal, termasuk intervensi kognitif menjadi hal yang utama untuk mencegah suatu gangguan regulasi dopamine [21].

Neurodevelopmental model pada skizofrenia menunjukkan bahwa defisit kognitif merupakan akibat sebuah penyimpangan dari perkembangan otak di tahap awal, namun tetap ada sebuah kemungkinan bahwa perubahan kognitif tersebut terus berjalan ketika penyakit berkembang [7].

\section{Defisit Kognitif}

Penurunan fungsi kognitif berkaitan dengan gangguan dalam banyak area di otak, termasuk diantaranya basal ganglia, kortek frontal, pendengaran dan kortek parietal, kortek orbital dan sistem limbik, termasuk hippocampus. Studi neuroimaging postmortem mengungkapkan penurunan materi abu-abu dan materi putih serta terjadi peningkatan volume ventrikel di dalam otak baik pada pasien skizofrenia dengan onset akut ataupun kronis. Di masa depan, analisis ini nantinya akan menunjukkan terganggunya hubungan interneuron yang berhubungan dengan kognitif yaitu hubungan interneuron pada jalur glutamatergic, gama amino butyric acid (GABAergic), dan acetylcholinergic [15].

\section{Neurobiologi dari Defisit Kognitif pada Skizofrenia}

Terdapat 3 jalur utama yang terkait penurunan kognitif pada skizofrenia, dopaminergic, glutamatergic, dan sistem kolinergik. Ketiga jalur ini juga terkait dengan patofisiologi dari Skizofrenia. Kelainan pada jalur ini mengakibatkan gangguan kognitif pada Skizofrenia [15].

\section{Sistem Dopaminergic}

Data dari studi pasien dengan skizofrenia telah menunjukkan peningkatan kadar dopamin di area kortikal, dengan kenaikan yang terlihat pada reseptor D2 prasinaptik dan striatum. Pada kortek prefrontal, transmisi dopaminergik terutama dimediasi oleh reseptor D1 sehingga memberikan peran substansial bahwa korteks prefrontal berperan pada fungsi kognisi. Telah diduga bahwa disfungsi reseptor D1 dapat memediasi timbulnya beberapa hendaya kognitif dan gejala-gejala negatif pada pasien skizofrenia. 
Pengamatan ini mendukung bahwa saat ini antipsikotik yang memiliki afinitas yang kuat pada reseptor D2 mengurangi gejala positif penyakit namun tidak berpengaruh pada perbaikan gangguan kognitif. Hal ini terlihat dalam penelitian Clinical Antipsychotic Trials of Intervention Effectiveness (CATIE), yang tidak menemukan perbedaan yang signifikan dalam peningkatan kognitif dalam salah satu dari kelompok perlakuan (yang menerima antipsikotik generasi pertama dan mereka yang menerima 1 dari 4 antipsikotik generasi kedua) setelah 2 bulan pengobatan. Dopamin telah terbukti target yang layak untuk memperbaiki gejala positif. Namun, hanya menarget dopamin tidak cukup kuat untuk mengurangi kerusakan kognitif pada skizofrenia [15].

\section{Sistem Glutamatergic}

Bukti-bukti menunjukkan bahwa kelainan pada transmisi glutamat juga berkontribusi pada patogenesis skizofrenia, khususnya kognitif dan defisit pengolahan sensorik. Teori ini didasarkan pada kenyataan bahwa glutamatergic $N$-metil-d-aspartat (NMDA) antagonis, seperti phencyclidine (PCP) dan ketamin, dapat menginduksi psikosis dan menurunkan fungsi kognitif.

Penelitian menunjukkan bahwa sistem NMDA memainkan peran kunci dalam neuroplastisitas, sinkronisasi saraf, dan konektivitas sinaptik. Efek utama dari NMDA adalah modulasi GABAergic ke interneuron yang dianggap terkait pada fungsi kognitif. Disfungsi dari NMDA dapat secara signifikan mengganggu sinkronisasi jaringan interneuron pada skizofrenia, yang kemudian dapat menyebabkan gangguan neuroplastisitas [15].

\section{Sistem Asetilkolin}

Dalam sistem saraf pusat, neurotransmisi acetylcholinergic secara integral terlibat dalam aspek pembentukan memori, afek, perilaku dan motivasi. Kesemua aspek kognitif tersebut terganggu pada skizofrenia. Fungsi-fungsi kognitif dan perilaku tersebut dimodulasi oleh reseptor Achetilcholine $\alpha 7$. Oleh karena itu, berubahnya neurotransmisi asetilkolin dapat berkontribusi untuk gejala kognitif dan perilaku pada skizofrenia.

\section{Tanda-tanda Kerusakan Kognitif}

Tanda dari kerusakan kognitif dapat muncul beberapa tahun sebelum episode pertama psikotik akut. Tandatanda ini belum termasuk bukti penurunan kinerja akademis saat usia dini, yang menjadi lebih jelas selama sekolah menengah dan lanjut. Pada masa remaja, tingkat IQ premorbid pada mereka yang kemudian berkembang menjadi skizofrenia, terjadi penurunan kurang lebih 8 poin di bawah normal.

\section{Implikasi dalam intervensi}

Penjelasan tentang adanya kerusakan fungsi kognitif mengharuskan kita mengambil suatu tindakan. Penurunan fungsi yang terjadi dapat bermakna 2 hal, merupakan akibat terhambatnya proses maturasi dari perkembangan kemampuan kognitif, atau merupakan sebuah perubahan "neuroprogressive" sebagai akibat perjalanan penyakit dimana kemampuan tersebut sebenarnya sudah mengalami maturasi pada usia pra-remaja. Sehingga, strategi remediasi kognitif merupakan salah satu intervensi yang saat ini penting untuk dilakukan sebagai sebuah intervensi dini pada pasien skizofrenia $[17,21]$.

Cognitive Enhancement Therapy (CET) saat ini menjadi salah satu pendekatan yang cukup baik pada terapi remediasi kognitif pada skziofrenia. CET menunjukkan perkembangan yang signifikan pada neurokognitif dan fungsi sosial-kognitif terutama pada pasien onset dini skizofrenia, disaat studi farmakologi dari penggunaan antipsikotik pada onset dini skizofrenia tidak menunjukkan perkembangan yang terlalu baik terhadap kognitif sosial dan nonsosial [17].

\section{COGNITIVE ENHANCEMENT THERAPY}

\section{Sejarah CET}

Cognitive Enhancement Therapy pertama kali dikembangkan dan diuji pada awal hingga pertengahan 1990an sebagai pendekatan terintegrasi dari perbaikan kemampuan neurokognitif dan sosial kognitif [22]. Konsep CET sendiri dikembangkan dari Integrated Psychological Therapy (IPT) yang digunakan pada pasien skizofrenia dan terapi kognitif pada pasien cedera kepala. Titik berat pelatihan ini begeser dari bentuk verbatim (pemrosesan informasi kognitif secara kongkrit yang ditandai dengan lebih dini dan tidak terlalu rumit) menjadi lebih ke arah inti atau pokok dan abstraksi spontan dari tema-tema yang berhubungan. Sehingga pasien distimulasi untuk berpikir sebagai seorang dewasa, bukan lagi seorang remaja atau usia prapubertas [23].

Paling tidak ada 4 tujuan utama dari CET:

1. Memfasilitasi kembalinya fungsi sosiokognitif. Tujuan kedua dari CET adalah mengembangkan pola perilaku yang sesuai dengan konteks sosial, meningkatkan kesadaran terhadap respon seseorang dan efeknya terhadap 
orang lain.

2. Meningkatkan kemampuan pasien untuk melakukan komunikasi dengan orang lain.

3. Mengembangkan pemahaman pasien terhadap sakit yang diderita (skizofrenia) dengan menyediakan program edukasi dimana didalamnya pasien memahami adanya penurunan kemampuan kognitif sosial dan nonsosial.

4. Tujuan keempat dari CET adalah memberikan sebuah pengalaman yang ditujukan untuk mempengaruhi kemampuan kognitif nonsosial [23-24].

\section{Model CET}

Saat ini sangat banyak terapi-terapi remediasi kognitif yang digunakan pada pasien skizofrenia kurang lebih sekitar 4 dekade terakhir. Mulai dari Integrated Psychological Therapy (IPT) pada tahun 1970 yang menjadi dasar pengembangan CET, Cognitive Enhancement Therapy pada tahun 1992, Integrated Neurocognitive Therapy (INT), termasuk Cognitive Remediation (CR). Namun, CET memiliki kekhususan dibandingkan terapi remediasi kognitif yang lain. CET mengembangkan bahwa remediasi kognitif akan maksimal memberikan hasil bila tidak hanya kognitif umum saja yang diperbaiki, namun juga tentang kognitif sosial. Dengan kombinasi tersebut, pemulihan atau rekoveri pasien bisa lebih baik dan target pengembalian fungsi keseharian pasien bisa tercapai dengan baik.

\section{Cognitive Enhancement Therapy (CET) dikatakan} mengkombinasikan selain kognitif sosial dan non sosial, CET juga mengkombinasikan cara terapi yang dilakukan. CET mengkombinasikan antara remediasi kognitif berbasis kognitif umum dengan program komputer atau pelatihan standar yang bersifat mendidik dengan sebuah interaksi sosial baik secara individu ataupun kelompok. Adanya interaksi sosial pada CET bertujuan agar pasien mendapatkan sebuah pengalaman yang bisa digunakan dalam kehidupan. Selain itu, interaksi sosial akan memberikan stresor untuk pasien dimana dengan begitu, pasien dapat mencoba beradaptasi menghadapinya. Diharapkan dengan stresor yang didapat selama proses terapi, pasien memiliki mekanisme yang cukup baik dalam menghadapi stresor tersebut jika nantinya selesai terapi [22-23].

\section{Tahapan CET}

Cognitive Enhancement Therapy memiliki 2 komponen dasar kognitif yang diperbaiki, kognitif sosial dan nonsosial. Kognitif nonsosial yang dimaksud adalah kemampuan neurokognitif pasien. Secara umum gambaran pelaksa- naannya dilakukan setiap minggu sekali dengan durasi 2 kali 1-1,5 jam dalam sekali sesi. Dalam pelaksanaannya tetap digunakan psikoterapi supportif, obat antipsikotik, ketentuan layanan dasar seperti, hak untuk makan, menggunakan pakaian yang layak, dan selter [24].

\section{Metode CET}

Metode yang digunakan pada CET adalah melakukan pendekatan terhadap disabilitas pada skizofrenia melalui gejala yang ditunjukkan yang berkaitan dengan domain kognitif yang mengalami kerusakan. Pada umumnya, gejala yang muncul pada pasien skizofrenia terkait kerusakan kognitif yang mendasari. Metode yang dilakukan CET kemudian memberikan perbaikan pada gangguan fungsi tersebut dengan melakukan latihan. Diharapkan nantinya pengalaman selama latihan yang dilakukan memberikan efek terhadap perbaikan fungsi kognitif [24].

\section{Peningkatan Kemampuan Kognitif Nonsosial}

Kemampuan kognitif nonsosial yang menjadi target untuk dikembangkan adalah atensi, memori, dan penyelesaian masalah. Beberapa literatur mengatakan bahwa fungsi kognitif ini merupakan dasar dari keahlian untuk berinteraksi sosial dengan orang lain. Latihan ini dilakukan kurang lebih 2,5 jam dalam 1 minggu selama 6 bulan kedepan. Metode ini diadaptasi dari Program Rehabilitasi Ben-yishay untuk pasien dengan cidera kepala [24].

\section{Peningkatan Kemampuan Kognitif Sosial}

Proses terapi untuk meningkatkan kemampuan kognitif sosial dimulai dari sebuah kelompok kecil dengan memulai latihan bersosialisasi dimana secara alami membantu pasien untuk mahir dalam mengambil sebuah kesimpulan terkait permasalahan sosial yang sedang dibicarakan dengan menggunakan kemampuan kognitif nonsosial yang telah dilatih sebelumnya (kemampuan atensi, memori, dan penyelesaian masalah). Kesulitan permasalahan yang akan dibahas akan semakin meningkat seiring dengan perkembangan yang ditunjukkan oleh pasien. Terapis juga akan melakukan beberapa petunjuk dan pendampingan selama proses latihan [24].

Proses terapi kognitif nonsosial dilakukan dengan sebuah format terstruktur selama 1,5 jam setiap pekan dan dilakukan selama kurang lebih 56 pekan. Kemudian latihan akan ditambahkan selama 6 pekan dengan mengurangi secara bertahap petunjuk atau pendampingan dari terapis [24]. 
CET yang dilakukan diadaptasi dari pengunaan CET pada cidera otak oleh Ben-Yishay yang dilakukan selama 6 jam dalam satu sesi, 4 hari dalam seminggu dan selama 20 minggu. CET pada skizofrenia hanya dilakukan selama 1,5 jam setiap sesi untuk mencegah kelelahan yang terjadi pada pasien dikarenakan pasien skizofrenia lebih sensitif terhadap stresor [24].

\section{Efektivitas CET}

Pasien skizofrenia yang masuk kategori pasien baru dengan durasi sakit kurang lebih 2 tahun adalah termasuk pasien yang utama untuk mendapatkan CET. Beberapa studi mengatakan bahwa CET sangat efektif sebagai sebuah intervensi dini pasien-pasien dengan skizofrenia. Intervensi dini yang dilakukan bertujuan agar pemulihan pasien bisa lebih cepat dan lebih baik untuk kembali ke fungsi kehidupan sehari-hari [13,17]. Namun, pada pasien skizofrenia dengan durasi sakit lebih dari 2 tahun pun, CET masih memberikan perbaikan yang signifikan. Sehingga, CET dapat diberikan pada pasien dengan durasi sakit lama ataupun baru, meskipun lebih baik digunakan sebagai sebuah intervensi dini pada gangguan kognitif pasien skizofrenia [22].

\section{RINGKASAN}

Skizofrenia adalah gangguan jiwa yang kronis, parah, melemahkan, dan disabilitas atau kecacatan. Sekitar 98\% pasien dengan Skizofrenia tidak dapat kembali remisi. Faktor yang menyebabkan disabilitas adalah penurunan fungsi kognitif. Penurunan fungsi kognitif pada pasien skizofrenia disebabkan adanya gangguan neurodevelopmental dan neurodegeneratif dari otak. Penurunan fungsi kognitif terkait dengan sistem Dopaminergic, Glumatatergic, dan Asetilkolinergic. Penggunaan obat antipsikotik yang hanya bekerja di sistem Dopamin tidak memberikan perbaikan pada fungsi kognitif sehingga dibutuhkan modalitas terapi lain untuk perbaikan fungsi kognitif.

Cognitive Enhancement Therapy adalah salah satu terapi tambahan yang digunakan untuk perbaikan fungsi kognitif sosial dan nonsosial pada pasien. Tujuan dari CET adalah memfasilitasi kembalinya fungsi sosiokognitif, mengembangkan pola perilaku pasien terhadap kondisi sosial yang terjadi, mengembangkan pemahaman pasien terhadap sakit yang diderita (Skizofrenia) serta dampaknya terhadap penurunan kemampuan kognitif, dan memberikan sebuah pengalaman dan latihan yang ditujukan untuk memperbaiki kemampuan kognitif nonsosial (aspek atensi, memori, dan penyelesaian masalah). Penggunaan CET baik pada onset awal maupun kronis pada pasien skizofrenia menunjukkan adanya perbaikan kemampuan kognitif pasien yang ditunjukkan dengan pasien bisa bekerja kembali. CET sendiri mulai digunakan sebagai langkah intervensi dini terhadap penurunan kognitif pasien dengan Skizofrenia. CET mulai dikembangkan, tidak hanya digunakan pada pasien Skizofrenia saja, namun juga pada pasien Skizoafektif, Skizofrenia yang berkomorbid dengan penyalahgunaan zat, serta pasien autisme. Diharapakan, peningkatan kualitas hidup pada pasien bisa tercapai dengan pemberian kombinasi antara farmakoterapi dan Cognitive Enhancement Therapy.

\section{DAFTAR PUSTAKA}

[1] C. Iorizzo, Schizophrenia and Other Psychotic Disorder, First. New York, USA: Crabtree Publishing Company, 2014.

[2] S. C. Schulz, M. F. Green, and K. J. Nelson, Schizophrenia and Psychotic Spectrum Disorder, First. New York, USA: Oxford University Press, 2016.

[3] B. J. Sadock and V. A. Sadock, Kaplan \& Sadock's Synopsis of Psychiatry: Behavioral Sciences/Clinical Psychiatry, 11th ed. Wolters Kluwer, 2014.

[4] K. Malik and U. Indonesia, "Journal of International Dental and Medical Research ISSN 1309-100X http:// www.jidmr.com Remission of Schizophrenia in Indonesia Khamelia Malik and et al,” J. Int. Dent. Med. Res., vol. 12, no. 1, pp. 238-241, 2019.

[5] R. Schennach et al., "Remission in schizophrenia What are we measuring? Comparing the consensus remission criteria to a CGI-based definition of remission and to remission in major depression," Schizophr. Res., vol. 209, pp. 185-192, 2019.

[6] R. S. E. Keefe and P. D. Harvey, "Cognitive Impairment in Schizophrenia," in Novel Antischizophrenia Treatments, First., M. A. Geyer and G. Gross, Eds. USA: Springer Berlin Heidelberg, 2012, pp. 11-38.

[7] Y. B. Noor and M. S. Mahajuddin, "Efek Terapi Remediasi Kognitif Terhadap Perbaikan Fungsi Kognitif Pasien Skizofrenia dengan Terapi Standar Rawat Jalan di RSJ Menur Surabaya," Universitas Airlangga, 2015.

[8] B. T. Talreja, S. Shah, and L. Kataria, "Cognitive Function in Schizophrenia and Its Association with Socia-demographics factors," Ind. Psychiatry J., vol. 22, no. 1, pp. 47-53, 2013. 
[9] G. Oaks, S. R. Marder, R. J. Hu, and G. Alva, "Cognitive Impairment in Schizophrenia: Understanding Prevalence , Magnitude , and Scope," in Current Psychiatry, 2014, pp. 1-8.

[10] W. F. Maramis and A. A. Maramis, Catatan ilmu kedokteran jiwa, 2nd ed. Surabaya: Airlangga University Press, 2009.

[11] M. S. Keshavan, S. M. Eack, K. M. Prasad, C. S. Haller, and R. Y. Cho, "Longitudinal functional brain imaging study in early course schizophrenia before and after cognitive enhancement therapy," Neuroimage, vol. 151, pp. 55-64, 2017.

[12] J. A. Wojtalik and S. M. Eack, "Cognitive Enhancement Therapy Improves Social Relationships Quality of Life among Individuals with Schizophrenia Misusing Substances," Soc. Work Res., vol. 43, no. 1, pp. 59-63, 2019.

[13] S. M. Eack et al., "Cognitive enhancement therapy for early-course schizophrenia: Effects of a two-year randomized controlled trial," Psychiatr. Serv., vol. 60, no. 11 , pp. 1468-1476, 2009.

[14] M. of H. R. of Indonesia, "Riset Kesehatan Dasar (National Health Survey)," Minist. Heal. Repub. Indones., no. 1, pp. 1-303, 2013.

[15] S. Grover and N. Malhotra, "Depression in elderly: A review of Indian research,” J. Geriatr. Ment. Heal., vol. 2, no. 1, pp. 4-15, 2015.

[16] S. M. Eack et al., "Cognitive Enhancement Therapy in substance misusing schizophrenia : Results of an 18 -month feasibility trial," Schizophr. Res., vol. 161, no. 2-3, pp. 478-483, 2015.

[17] S. M. Eack, D. P. Greenwald, S. S. Hogarty, and M. S. Keshavan, "One-year durability of the effects of cognitive enhancement therapy on functional outcome in early schizophrenia," Schizophr. Res., vol. 120, no. 1-3, pp. 210-216, 2010.

[18] K. E. Lewandowski, S. M. Eack, S. S. Hogarty, D. P. Greenwald, and M. S. Keshavan, "Is cognitive enhancement therapy equally effective for patients with schizophrenia and schizoaffective disorder?," Schizophr. Res., vol. 125, no. 2-3, pp. 291-294, 2011.

[19] S. M. Eack, R. I. Mesholam-gately, D. P. Greenwald, S. S. Hogarty, and M. S. Keshavan, "Negative symptom improvement during cognitive rehabilitation :
Results from a 2-year trial of Cognitive Enhancement Therapy," Psychiatry Res., vol. 209, no. 1, pp. 21-26, 2013.

[20] T. Wykes and C. Reeder, Cognitive Remediation Therapy for Schizophrenia, First. New York, USA: Routledge, 2005.

[21] C. Pantelis, C. Wannan, C. F. Bartholomeusz, K. Allott, and P. D. Mcgorry, "Cognitive intervention in early psychosis — preserving abilities versus remediating deficits," Curr. Opin. Behav. Sci., vol. 4, pp. 63 $-72,2015$.

[22] G. E. Hogarty et al., "Cognitive enhancement therapy for schizophrenia," Lancet, vol. 364, no. 9452, pp. 2163-2165, 2004.

[23] V. Roder, L. Hulka, and A. Medalia, "Combined Treatment Approaches: Overview and Empirical Results," in Neurocognition and Social Cognition in Schizophrenia Patients. Basic Concepts and Treatment, vol. 177, V. Roder and A. Medalia, Eds. Karger, 2010, pp. 85-103.

[24] G. E. Hogarty and S. Flesher, "Practice principles of cognitive enhancement therapy for schizophrenia," Schizophr. Bull., vol. 25, no. 4, pp. 693-708, 1999. 